(C) 2018 IEEE. Personal use of this material is permitted. Permission from IEEE must be obtained for all other uses, in any current or future media, including reprinting/republishing this material for advertising or promotional purposes, creating new collective works, for resale or redistribution to servers or lists, or reuse of any copyrighted component of this work in other works.

\title{
DETECTING MICROPLASTICS POLLUTION IN WORLD OCEANS USING SAR REMOTE SENSING
}

\author{
Narangerel Davaasuren ${ }^{1}$, Armando Marino ${ }^{2}$, \\ Nicolas Ackermann ${ }^{3}$, Matteo Alparone ${ }^{4}$, Ferdinando Nunziata $^{4}$, Carl Boardman ${ }^{1}$ \\ ${ }^{1}$ School of Engineering and Innovation, The Open University, Walton Campus, MK7 6AA, United \\ Kingdom; ${ }^{2}$ University of Stirling, United Kingdom; \\ ${ }^{3}$ Swiss Federal Railways SBB, Luzern, Switzerland; ${ }^{4}$ The Parthenope University of Naples, Italy
}

\begin{abstract}
Plastic pollution in the world's oceans is estimated to have reached 270.000 tones, or 5.25 trillion pieces. This plastic is now ubiquitous, however due to ocean circulation patterns, it accumulates in the ocean gyres, creating "garbage patches". This plastic debris is colonized by microbes and microorganisms that create unique ecosystems of sea-slicks and microbial bio-films. Microbial colonization is the first step towards disintegration and degradation of plastic materials: a process that releases metabolic byproducts from energy synthesis. These by-products include the release of short-chain and more complex carbon molecules in the form of surfactants, which we hypothesize will affect the fluid dynamic properties of waves (change in viscosity and surface tension) and make them detectable by SAR sensor.

In this study we used Sentinel-1A and COSMO-SkyMed SAR images in selected sites of both the North Pacific and North Atlantic oceans, close to ocean gyres and away from coastal interference. Together with SAR processing we conducted contextual analysis, using ocean geophysical products of the sea surface temperature, surface wind, chlorophyll, wave heights and wave spectrum of the ocean surface. In addition, we started experiments under controlled conditions to test the behavior of microbes colonizing the two most common pollutants, polyethylene (PE) and polyethylene terephthalate (PET) microplastics. The analysis of SAR images had shown that the speed of surface wind supplemented by accumulation mechanism of Langmuir cells is found to be a main meteorological factor influencing the distinct appearance of the sea-slicks and microbial biofilms. The preliminary conclusion of our study is that SAR remote sensing may be able to detect plastic pollution in the open oceans and this method can be extended to other areas.
\end{abstract}

Index Terms - Microplastics, Detection of surfactants, bio-films, SAR, Sentinel-1A, COSMO-SkyMed

\section{INTRODUCTION}

Plastic pollution is a global problem because of the harmful effects on marine life caused by ingestion and the subsequent bioaccumulation of pollutants [1]. Plastic particles have the potential to transfer via trophic level from mesozooplankton to a higher level -macrozooplankton and uptake and transport of pollutants. The total weight of microplastics $(<0.33 \mathrm{~mm}-1.00 \mathrm{~mm})$ in the North Pacific is estimated as $21 \times 10^{8}$ tons and in the North Atlantic as 10.4 $\mathrm{x} 10^{8}$ tons [2]. The floating plastic debris will form new habitat- plastisphere. The microbial bio-films on their surfaces will be different to their surroundings in terms of community structure and will play an important role in degradation of plastic via physical or metabolic means [3]. The other associated processes in the plastisphere will be related with an increase of microbial biomass [4] and subsequent processes- release of surfactants and formation of sea-slicks and bio-films [5], accompanied by change in viscosity and surface tension at the sea-surface microlayer (SML).

The main objective of our research is to identify sites polluted by microplastics using SAR sensors in detecting sea-slicks and bio-films over the ocean surface (dark patches in grayscale intensity SAR images), otherwise not visible in optical images. The other component affecting the distinct appearance of the sea-slicks and bio-films are Langmuir cells. They elicit accumulation of surfactants, sea-slicks and natural bio-films at the SML and possibly modify the fluid dynamic properties, thus suppressing the capillary waves [6]. These suppression effects on capillary waves are detectable by SAR sensor and therefore this can assist us in the identification of areas contaminated by microplastics. The remote sensing analysis was carried out together with the start of experiments under controlled conditions. To understand the processes associated with the colonization of polyethylene (PE) and polyethylene terephthalate (PET) microplastics, we started laboratory experiments. The final objective of our research is to develop an automated algorithm, grounded on SAR data, to detect presumably plastic contaminated areas in the open ocean, using the 
effects from surfactants, sea-slicks and microbial bio-films. This piece of research could represent a key point to support and assist in compiling an inventory of microplastics and to expand our overall understanding of related processes.

\section{SURFACTANTS, SEA-SLICKS AND MICROBIAL BIO-FILMS AT THE SEA-SURFACE (SML) LAYER}

The degradation and disintegration processes of plastic debris will be followed by the release of surfactants and formation of sea-slicks, bio-films, generally not visible in optical images. The formation of bio-films will be initiated by the attachment of proteins, followed by individual bacteria, which then trigger other microbial species to colonize. In Atlantic Ocean the bio-films are consist of bacteria, fungi, diatoms, protozoans, larvae, and algal spores embedded in an extracellular polymeric substance matrix [7]. The additional release of surfactants at the SML will be caused by more soluble organic components from the seaslicks and bio-films. We hypothesize that microbes colonizing microplastics will produce surfactants and radar sensor will see sea-slicks and bio-films as a dark spots (Figure 1).

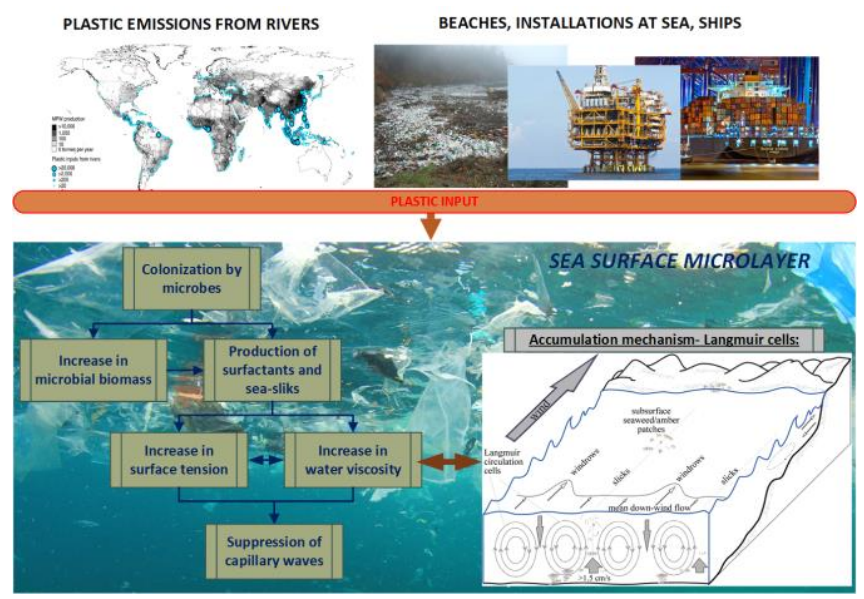

Figure 1- Processes associated with plastic input.

According to our hypothesis, these dark spots may be linked to microbiological colonization of microplastics. The modification of fluid dynamic properties of the SML, seen as suppression of capillary waves can be described as a mechanism of resonant microwave scattering from the wave spectrum, presented on SAR images as an absence of Bragg scattering [8].

Findings suggested that no clear relationship is found between surfactant activity at the SML and the total chlorophyll production [9]. However, the high ambient wind speed of $>12 \mathrm{~m} / \mathrm{s}^{-1}$ has an essential role in continuous supply of surfactants by bubble scavenging from the lower water column [10]. The nonionic soluble surfactants are able to suppress the wave tension forces, reduce the net oceanic $\mathrm{CO}_{2}$ uptake in $15-50 \%$ and to introduce a large dampening effect on air-sea exchange of $\mathrm{N}_{2} \mathrm{O}$. The highest concentration of plastic in the eastern North and South Pacific Oceans is found between $25^{\circ} \mathrm{N}-41^{\circ} \mathrm{N}$ latitude, according to 11 years sampling data (from 2001 to 2011), corresponding to the area of the Great Pacific Garbage Patch [11]. The accumulation mechanism of the Langmuir cells and low wind speed is found to be a main meteorological factor influencing the distinct appearance of the sea-slicks and bio-films [12]. The impact from Langmuir cells is related to accumulation effect to concentration of the surfactants and sea-slicks, and possible initiation of increase in surface tension at SML, which can be modelled as a surface force per unit volume, described by continuum surface force model (CSF) [13].

\section{DETECTING MICROPLASTIC POLLUTION USING SAR REMOTE SENSING}

The longstanding presence of plastic debris remaining in the near-surface of the ocean for up to 30 month and possibly longer [11], can provide the opportunity for repeated SAR acquisitions to monitor selected sites. Because the plastic concentration is not sufficient to change the ocean color and due to transparency of surfactant-associated bacteria and bio-films these features are not visible in optical images.

A similar study on detecting natural surfactants in the Gulf of Mexico was considered processing large datasets of C-band Radarsat-1 SAR images. They found the optimum wind speed and incidence angle range (from 3.5 to $7.0 \mathrm{~ms}^{-1}$ and from $22^{\circ}$ to $40^{\circ}$, respectively) to observe those slicks in SAR imagery [14]. The polarimetric SAR technique and image segmentation were successfully applied to detect marine pollution (oil spills and biogenic films), based on the dependency of subsurface wind and slicks on the sea surface [15]. The separation of polarization difference (PD) and a non-polarization (NN) components using the Bragg scattering model was applied on C-band Radarsat-2 quadpolarized SAR data in VV and $\mathrm{HH}$ polarizations to find a high suppression of NN backscatter by surfactants films [8]. The effects from the activity of surfactant-associated bacteria is also difficult to spot during in-situ sampling, mentioned in the attempt to synchronize acquisition of Radarsat-2 and TerraSAR-X satellite data and in-situ sampling [14].

In our study we used VV-polarized SAR images due to the clearer and more distinct dark signatures. However, we observed low standard deviation of wind values ranging from 0.12 to maximum $4.44 \mathrm{~ms}^{-1}$, measured by Aquarius and CERSAT scatterometer, indicating a matching distribution of these SAR signatures within the selected wind range. Additionally, we considered ancillary information on 
ship discharge based on ship traffic to separate plastic contaminated areas.

\section{RESULTS}

\subsection{SAR dataset}

The North Atlantic area is covered by Sentinel-1A images, provided by European Space Agency (ESA) Copernicus program, in Level 1, Extra Wide Swath (EW) Ground Range Detected (GRD), in full resolution 25 by 25 meters. The dataset include latest Sentinel-1A acquisition from November 03, 2017. The North Pacific area is covered by COSMO-SkyMed, StripMap HIMAGE, Level 1B (DGM), full resolution after resampling 4 by 20 meters.

Figure 2 shows VV-polarized SAR image acquired by Sentinel-1A in the North Atlantic. In this figure we can observe dark areas whose shape is sometimes patched sometimes linear. Similar stripes and "ring-like" signature can be observed in the middle of the Pacific Ocean (far from shipping routes and any other anthropogenic activity) from the COSMO-SkyMed image (Figure 3).

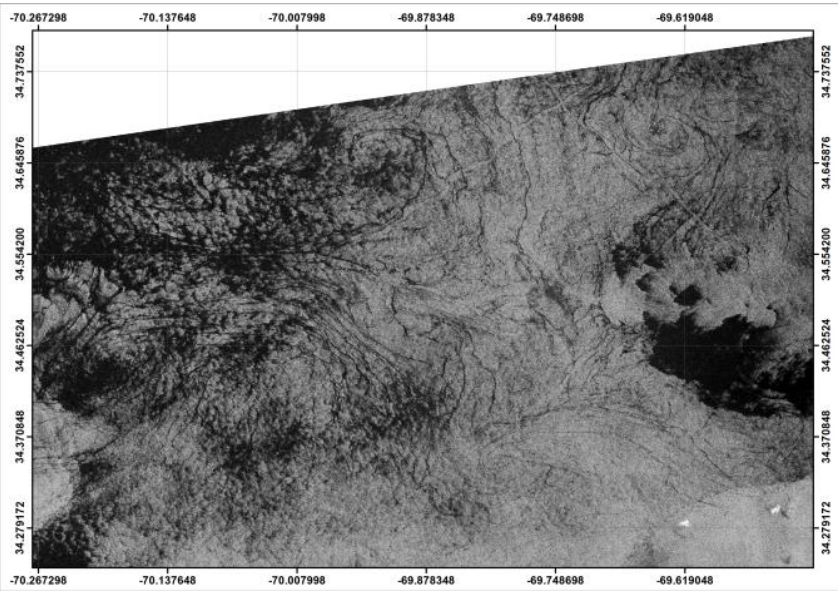

Figure 2- Sentinel-1A SAR with presumed surfactants and sea-slicks. Date of acquisition-03/11/17, 22:00 pm.

Comparing images, it appears that there are areas of low wind $\left(0.12\right.$ to $\left.4.44 \mathrm{~ms}^{-1}\right)$ that may cause the black patches over the sea surface. However, in areas where the wind is higher (starting from $6 \mathrm{~ms}^{-1}$ ) we can observe strikes that are generally associated with oil spills. These are not wind features and we hypothesize they are related to surfactants.

Since areas are far from high shipping traffic and considering low primary productivity (chlorophyll-a) of the Atlantic Ocean, we hypothesize they are due to bacterial activity associated with microplastics. Although this is not shown in the images, the direction of sea-slicks and biofilms in general will follow wind direction.

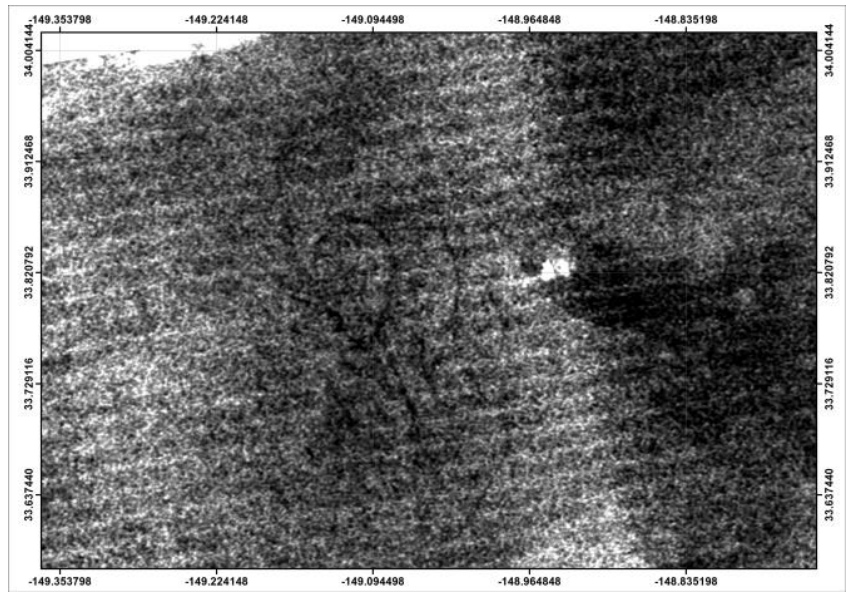

Figure 3- COSMO-SkyMed SAR with presumed surfactants and sea-slicks. Date of acquisition-16/06/13, 15:45 pm.

The areas with dark signatures fall within the microplastics contaminated areas, as is shown in Figure 4- in maps of the solutions of microplastics count, referred by us as in-situ data. The maps show high concentrations over North Atlantic and North Pacific ocean areas [16].
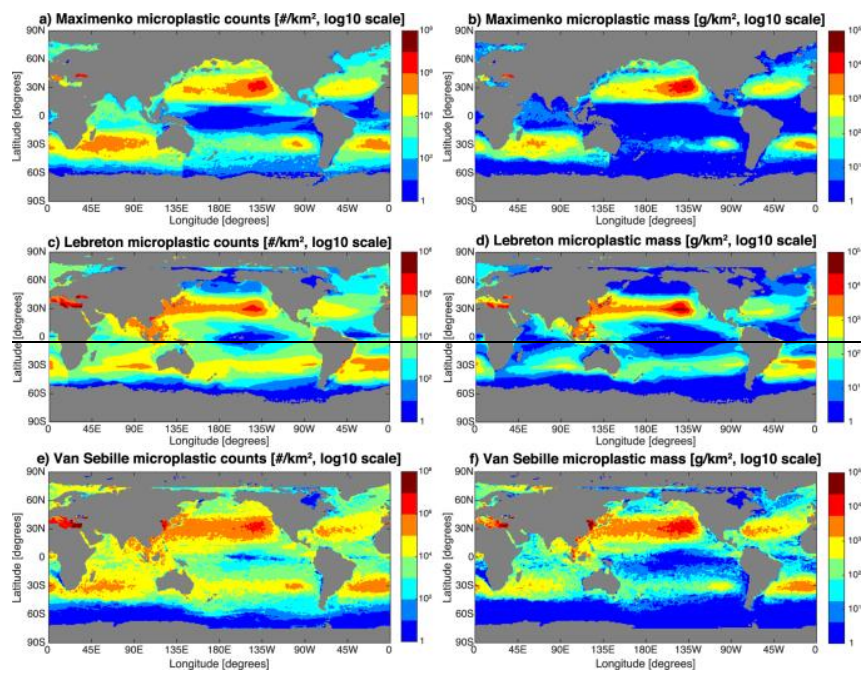

Figure 4- Maps of the solutions of microplastics count.

\subsection{Future experiments on surfactants}

In addition, we will carry experiments in controlled conditions by using the two most common microplasticspolyethylene (PE) and polyethylene terephthalate (PET) pollutants, to observe the effect of microbial colonization and release of surfactants. We will test the selected microplastics in two separate sets of aquariums and verify the results by two controls. To initiate the surfactants growth, in addition to artificial seawater $(70 \%)$, we will add $30 \%$ of actual seawater from the UK coast as a microbial 
inoculum. The seawater will be sampled in remote location far from estuaries, tributaries and settlements, to exclude unknown contamination. The spectral analysis of microplastics particles and samples of water is set to measure the relationship between surfactant concentration, wave amplitude and change in viscosity and surface tension.

\section{CONCLUSION}

The VV-polarized SAR images had distinct dark signatures which we presumed are related to microbiological activity related to colonization of microplastics. The correlation of these signatures showed dependency on a certain range of winds, from 0.12 to maximum $4.44 \mathrm{~ms}^{-1}$ and no relationship with chlorophyll-a. The research is still ongoing and the final objective is to develop an automated algorithm, grounded on SAR data using backscattering effect from surfactants, bio-films and sea-slicks. The algorithm will be aided by textual analysis and ancillary information and verified against data from microplastics count (Figure 3) and literature review. From preliminary findings we can conclude that possible sources of false alarms on our SAR images may be due to low wind areas (small waves with almost negligible roughness) and any other kind of oceanographic features, apart from Langmuir cells and Bragg scattering.

\section{ACKNOWLEDGEMENT}

COSMO-SkyMed Product - Copyright ASI 2016 processed under license from ASI - Agenzia Spaziale Italiana. Distributed by e-GEOS Sentinel-1A data were provided by ESA. This study is partly funded by the European Space Agency (ESA) in the framework of the Dragon-4 cooperation between ESA and Chinese Ministry of Science and Technology, project ID 32235.

\section{REFERENCES}

[1] O. Setälä, V. Fleming-Lehtinen, and M. Lehtiniemi, "Ingestion and transfer of microplastics in the planktonic food web," Environmental pollution, vol. 185, pp. 77-83, 2014.

[2] M. Eriksen, L. C. Lebreton, H. S. Carson, M. Thiel, C. J. Moore, J. C. Borerro, F. Galgani, P. G. Ryan, and J. Reisser, "Plastic pollution in the world's oceans: more than 5 trillion plastic pieces weighing over 250,000 tons afloat at sea," PloS one, vol. 9, no. 12, pp. e111913, 2014.

[3] E. R. Zettler, T. J. Mincer, and L. A. Amaral-Zettler, "Life in the "plastisphere": microbial communities on plastic marine debris," Environmental science \& technology, vol. 47, no. 13, pp. 7137-7146, 2013.

[4] P.-Y. Qian, S. C. Lau, H.-U. Dahms, S. Dobretsov, and T. Harder, "Marine biofilms as mediators of colonization by marine macroorganisms: implications for antifouling and aquaculture," Marine Biotechnology, vol. 9, no. 4, pp. 399-410, 2007.

[5] D. J. Carlson, "Surface microlayer phenolic enrichments indicate sea surface slicks," Nature, vol. 296, pp. 426, 04/01/online, 1982.

[6] R. A. Weller, and J. F. Price, "Langmuir circulation within the oceanic mixed layer," Deep Sea Research Part A. Oceanographic Research Papers, vol. 35, no. 5, pp. 711-747, 1988.

[7] M. Fischer, G. Triggs, and T. F. Krauss, "Optical sensing of microbial life on surfaces," Applied and environmental microbiology, vol. 82, no. 5, pp. 1362 1371, 2016.

[8] M. W. Hansen, V. Kudryavtsev, B. Chapron, C. Brekke, and J. A. Johannessen, "Wave breaking in slicks: Impacts on C-band quad-polarized SAR measurements," IEEE Journal of Selected Topics in Applied Earth Observations and Remote Sensing, vol. 9, no. 11, pp. 4929-4940, 2016.

[9] K. K. La Daana, R. Officer, O. Lyashevska, R. C. Thompson, and I. O'Connor, "Microplastic abundance, distribution and composition along a latitudinal gradient in the Atlantic Ocean," Marine pollution bulletin, vol. 115, no. 1, pp. 307-314, 2017.

[10] M. Eriksen, M. Thiel, and L. Lebreton, "Nature of Plastic Marine Pollution in the Subtropical Gyres," pp. 1-28, Berlin, Heidelberg: Springer Berlin Heidelberg.

[11] K. L. Law, S. E. Morét-Ferguson, D. S. Goodwin, E. R. Zettler, E. DeForce, T. Kukulka, and G. Proskurowski, "Distribution of Surface Plastic Debris in the Eastern Pacific Ocean from an 11-Year Data Set," Environmental Science \& Technology, vol. 48, no. 9, pp. 4732-4738, 2014/05/06, 2014.

[12] J. C. McWilliams, and P. P. Sullivan, "Vertical mixing by Langmuir circulations," Spill Science \& Technology Bulletin, vol. 6, no. 3-4, pp. 225-237, 2000.

[13] J. Brackbill, D. B. Kothe, and C. Zemach, "A continuum method for modeling surface tension," Journal of computational physics, vol. 100, no. 2, pp. 335-354, 1992.

[14] K. Howe, C. W. Dean, J. A. Kluge, A. Soloviev, A. Tartar, M. S. Shivji, S. Lehner, H. Shen, and W. Perrie, "DNA analysis of surfactant-associated bacteria in a natural sea slick observed by TerraSAR-X and RADARSAT-2 over the Gulf of Mexico," International Journal of Remote Sensing, pp. 1, 2017.

[15] A. Sineva, and A. Y. Ivanov, "Polarimetric radars and polarimetric SAR data in tasks of detection and identification of marine oil pollution," Izvestiya, Atmospheric and Oceanic Physics, vol. 52, no. 9, pp. 929-939, 2016.

[16] S. Erik van, W. Chris, L. Laurent, M. Nikolai, H. Britta Denise, A. v. F. Jan, E. Marcus, S. David, G. Francois, and L. Kara Lavender, "A global inventory of small floating plastic debris," Environmental Research Letters, vol. 10, no. 12, pp. 124006, 2015. 